J. Perinat. Med. 14 (1986) 411

\title{
Spatial filtering of the fetal electrocardiogram
}

\author{
Adriaan van Oosterom
}

Department of Medical Physics and Biophysics, University of Nijmegen, The Netherlands

\section{Introduction}

The fetal electrocardiogram (FECG) has been used in the past mainly as a relatively simple technique to obtain non-invasively an indicator of the fetal heart rate [12]. More recently interest has developed in the possibility of using the full information that is present in the waveform of the FECG signal [15]. Indications that the waveform of the FECG signal may indeed contain useful information for diagnostic purposes are presented in some of the other papers in this issue of this journal $[12,13]$.

One of the basic problems occuring in both applications (heart rate monitoring and waveform analysis) is the interference of the maternal ECG (MECG) in the recorded signals. Methods devised for suppressing the maternal contribution in the recorded signals obviously have to rely on differences in the characteristics of the FECG and the MECG. In the past various different characteristics have been used for this purpose such as differences in waveshape $[3,8]$, frequency content [14] and source location [2].

In this paper a method is described which is based on differences in the source location. The electrical sources of the fetal and of the maternal heart are clearly separated in space. By applying multiple abdominal leads a linear combination of the recorded signals can be formed which acts affectively as a spatial filter.

\section{Curriculum vitae}

ADRIAAN VAN OOSTEROM was born in Abcoude, The Netherlands, 1942. From 1961 to 1965 he trained as an Electronic Engineer at the Laboratory of Medical Physics, the University of Amsterdam, The Netherlands. $\mathrm{He}$ received the Masters degree in physics from the University of Amsterdam, in 1971. He re-

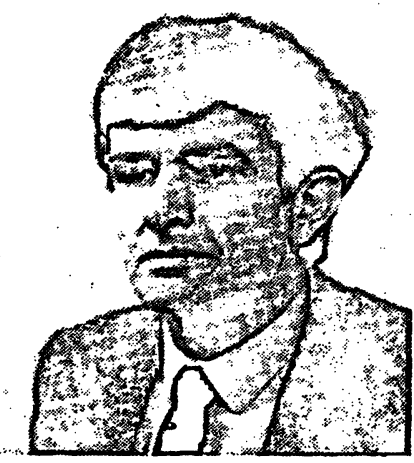
ceived the Ph.D. degree in physics, in 1978, from the University of Amsterdam, studying cardiac potential distribution.

From 1971 to 1982 he worked at the Laboratory of Medical Physics and the Department of Experimental Cardiology, the University of Amsterdam, where he researched the electrical activity of the heart. He is now a Professor of Medical Physics at the Catholic University of Nijmegen, The Netherlands. His main research interest is in the field of bioelectrical phenomena, particularly the study of the volume conductor aspect of potential theory.

As such the filter characteristics depend exclusively on the separation of the sources inside the female body and as such they can be expected to be independent of the temporal aspects of the recorded signals. In particular, the spatial filter is unaffected by the occurrence of ectopic beats in either the fetal or the maternal heart.

The design of the filter involves the determination of the weighting coefficients which are used 
to form such linear combination of the recorded signals that the MECG signal content present in this combination is minimized. The determination of these weighting coefficients is carried out by making use of a mathematical technique for analyzing the data matrix representing the digitized singnals in all simultaneously recorded leads known as the singular value decomposition (SVD). The procedure involves two steps. In the first step all possible linear combinations (weighting coefficients, to be represented as weighting vectors) of the recorded signals which result in a minimal MECG signal are identified. The next step searches for that combination of the weighting vectors found in the first step which results in a maximal FECG signal, based on maximal power in the QRS complex of the FECG in the filter output.

Since the first description of this method [11] it has been applied successfully in all cases considered for deriving a fetal trigger in a study on the complete representation of the electrical activity of the fetal heart as observable at the abdomen of pregnant women [10]. The main elements of the procedure will be outlined. In addition, a demonstration will be presented of the need for including the second step.

\section{Design of the spatial filter}

\subsection{Background}

The electrical generators of the fetal and of the maternal heart are rather complex sources which are distributed around their respective gross anatomical positions. The currents generated by these sources are conducted through the surrounding tissues and set up an electrical potential distribution at the body surface, which changes continuously with time in relation to the depolarization and repolarization sequences of the cells of the two hearts involved.

At relatively large distances from the sources the potential distributions can be described in terms of so-called equivalent generators [5]. Such generators have the properties that the electrical potentials set up by them are, at the (remote) observation points, indistinguishable from those of the actual cardiac sources. The current dipole is the best known of such equivalent generators and this concept has given rise to vector cardiography (VCG) [7]. In adult electrocardiography the VCG has been shown to be capable of accounting for only approximately $70 \%$ of the power present in the full potential distribution that can be observed at the body surface [5]. However, if remote observation points are used exclusively the dipole can be expected to account for up to $99 \%$ of the signal power. This is the case when abdominal electrodes are used. Both the maternal heart and the fetal heart are at a relatively large distance and thus a dipolar current source $\overrightarrow{\mathrm{m}}(\mathrm{t})$ and a fetal current source $\vec{f}(t)$ can be expected to be a proper equivalent source description for the electrical sources of the maternal as well as for those of the fetal heart.

To explain the principle of the filtering method we now, for the moment, assume that this description is completely valid.

The electrical signal $\Phi_{j}(t)$ as observed between any pair $j$ of abdominal electrodes can now be described as

$$
\begin{aligned}
\Phi_{j}(t)= & M_{j}(t)+F_{j}(t) \\
= & a_{j 1} m_{1}(t)+a_{j 2} m_{2}(t)+a_{j 3} m_{3}(t)+ \\
& b_{j 1} f_{1}(t)+b_{j 2} f_{2}(t)+b_{j 3} f_{3}(t),
\end{aligned}
$$

where $m_{k}(t),(k=1,3)$ are the components of the maternal dipole (generator) and

$f_{k}(t),(k=1,3)$ are the components of the fetal dipole (generator).

The terms $a_{j k},(k=1,3)$ and $b_{j k},(k=1,3)$ are transfer coefficients which represent the effect of the volume conduction in the medium. Their values are determined by the position of the pair $j$ of recording electrodes with respect to, respectively, the position of the maternal dipole and of the fetal dipole and by the values of the electrical conductivity of the various tissues between electrical source (heart) and the abdominal surface. Equation 1 can be expressed in a more compact form as

$\Phi_{j}(t)=\vec{a}_{j} \cdot \vec{m}(t)+\vec{b}_{j} \cdot \vec{f}(t)$ 
using the inner product - or dot product of vector algebra. This demonstrates that the transfer coefficients $a_{j k}$ and $b_{j k}(k=1,3)$ can be considered as the components of vectors $\vec{a}_{j}$ and $\vec{b}_{j}$ in three dimensional space. These are commonly known as the lead vectors related to the electrode pair (lead) $\mathrm{j}$ [1]. Note that these lead vectors are independent of time.

We now consider a time interval $T_{M}$ in which the maternal signal (QRS complex) is present, whereas the fetal signal is absent i.e. $\overrightarrow{\mathrm{f}}(\mathrm{t})=0$. During this time interval

$$
\begin{aligned}
\Phi_{j}(t)=M_{j}(t) & =\vec{a}_{j} \cdot \vec{m}(t) \\
& =a_{j 1} m_{1}(t)+a_{j 2} m_{2}(t)+a_{j 3} m_{3}(t) .
\end{aligned}
$$

If three different registrations $\Phi_{j}(t) ;(j=1,3)$ are available and if the corresponding transfer coefficients $a_{j k}$ are known it is possible to solve the system of three linear equations in the three unknown variables $\mathrm{m}_{1}(\mathrm{t}), \mathrm{m}_{2}(\mathrm{t})$ and $\mathrm{m}_{3}(\mathrm{t})$.

This means that these variables (the dipole strengths) can be expressed as a linear combination of the observed signals $M_{1}(t), M_{2}(t)$ and $\mathrm{M}_{3}(\mathrm{t})$. Any additional signal $\mathrm{M}_{\mathrm{j}}(\mathrm{t}) ;(\mathrm{j}>3)$ is a linear combination of $\mathrm{m}_{\mathrm{k}}(\mathrm{t}) ;(\mathrm{k}=1,3)$ by Eqn. 3, which are in turn linear combinations of $M_{1}(t), M_{2}(t)$ and $M_{3}(t)$ by the above arguement. This demonstrates that it is possible to express any recorded signal $\mathrm{M}_{\mathrm{j}}(\mathrm{t})$ as a linear combination of three suitably selected signals $\mathrm{M}_{1}(\mathrm{t}) ;(1 \neq \mathrm{j})$. The number three reflects the assumption that a dipole (having maximally three independent components) is the equivalent source. For more complex source descriptions, (e.g. multipole expansions [5]), having more than 3 independent source components the above derivation can be easily extended.

In practice the transfer coefficients $a_{j k}$ are usually not known. However, this does not alter the fact that any signal must be a linear combination of any suitable selection of three further signals from the collection of signals observed in time interval $T_{M}$. This means that factors $\alpha_{1}$, $\alpha_{2}, \alpha_{3}$ exist such that

$$
M_{4}(t)=\alpha_{1} M_{1}(t)+\alpha_{2} M_{2}(t)+\alpha_{3} M_{3}(t) .
$$

This equation may be scaled at will, and hence an equivalent way of expressing this result is

$\beta_{1} M_{1}(t)+\beta_{2} M_{2}(t)+\beta_{3} M_{3}(t)+\beta_{4} M_{4}(t)=0 .(5)$

From this representation it is clear that it should be possible to find such weighting coefficients $\beta_{1} ;(1=1,4)$ that the linear combination of the recorded signals $\Phi_{1}(\mathrm{t}) ;(1=1,4)$ produces zero over the time interval considered, and thus completely suppresses the MECG, which is the sole constituent to the signals during that interval $(\Phi(\mathrm{t})=\mathrm{M}(\mathrm{t}))$

During the remaining time of the observed signals the maternal contribution may (partly) coincide with fetal activity i.e.

$\Phi_{j}(t)=M_{j}(t)+F_{j}(t)$

This is a linear combination of maternal and fetal electrical activity based on the superposition principle. Applying the weighting coefficients $\beta$ to these signals we find

$$
\begin{gathered}
\mathrm{L}(\mathrm{t})=\beta_{1} \Phi_{1}(\mathrm{t})+\beta_{2} \Phi_{2}(\mathrm{t})+\beta_{3} \Phi_{3}(\mathrm{t})+\beta_{4} \Phi_{4}(\mathrm{t})= \\
\beta_{1} \mathrm{M}_{1}(\mathrm{t})+\beta_{2} \mathrm{M}_{2}(\mathrm{t})+\beta_{3} \mathrm{M}_{3}(\mathrm{t})+\beta_{4} \mathrm{M}_{4}(\mathrm{t})+ \\
\beta_{1} \mathrm{~F}_{1}(\mathrm{t})+\beta_{2} \mathrm{~F}_{2}(\mathrm{t})+\beta_{3} \mathrm{~F}_{3}(\mathrm{t})+\beta_{4} \mathrm{~F}_{4}(\mathrm{t})= \\
\beta_{1} F_{1}(\mathrm{t})+\beta_{2} F_{2}(\mathrm{t})+\beta_{3} F_{3}(\mathrm{t})+\beta_{4} F_{4}(\mathrm{t})
\end{gathered}
$$

in which equation 5 is used. This demonstrates that the set of weighting coefficients found during the time interval $T_{M}$ will completely wipe out the maternal component in the linear combination $\mathrm{L}(\mathrm{t})$ throughout the full recording period.

In forming the above linear combination one has no guarantee whatsoever that the linear combination has any appreciable fetal component. This problem can be overcome by recording many more (say $n$ ) abdominal signals than the required $4(n>4)$. The consequence of this is that several $(n-3)$ linear combinations may be formed, each having the property of suppressing the maternal signal. Any of the corresponding sets of weighting coefficients $\beta_{1}$; $(1=1, n)$ can be considered as a (column) vector of linear algebra. Any linear combination of these weighting vectors will still have the prop- 
erty of suppressing the maternal component. This creates the possibility of searching for that linear combination of the various filter outputs which results in an optimal fetal component in the filter output. This leaves us with two practical problems:

1) find all $n-3$ weighting vectors $\beta$ which leave no maternal component in the resulting linear combination of the observed abdominal signals.

2) find the linear combination of weighting vectors $\beta$ such that the fetal component in the (final) resulting linear combination of the observed abdominal signals is optimal.

These two problems will be treated in the next two subsections.

\subsection{Determination of the weights suppressing the MECG}

Signals are recorded between each of $n$ electrodes spaced over the abdomen and one common (abdominal) potential reference electrode. The observed signals are sampled and digitized. The resulting data can be expressed by the matrix $\Phi$ (dimension $m \times n$ ) of which the $n$ columns represent the signals recorded in leads $j ;(j=1, n)$ and the rows represent the samples taken at time instants $t_{i}=i \tau ;(i=$ $1, \mathrm{~m}) ; \tau=$ sampling interval $(2 \mathrm{~ms})$.

By visual inspection of the recorded signals a time interval containing $\mathrm{p}$ samples is identified in which the maternal complex is the sole constituent (besides noise). The corresponding data set is the matrix $M$ (dimension $p \times n$ ). The singular value decomposition SVD $[4,6]$ of this matrix is performed yielding

$\mathrm{M}=\mathrm{US} \mathrm{V}^{\mathrm{t}}$,

with

$\mathrm{U}$ an orthonormal matrix of dimension $\mathrm{p} \times \mathrm{p}$,

$\mathrm{S}$ a matrix (dimension $\mathrm{p} \times \mathrm{n}$ ) having nonnegative main diagonal elements only: the non-negative singular values of matrix $M$,

$\mathrm{V}$ an orthonormal matrix of dimension $\mathrm{n} \times \mathrm{n}$ $\left(\mathrm{V}^{\mathrm{t}}\right.$ is the transpose of this matrix).
Using the orthonormality of matrix $\mathrm{V}$ one finds

$\mathrm{MV}=\mathrm{US}$

which can be expressed as

$M v_{k}=u_{k} S_{k}$,

with $\mathrm{k}$ referring to the $\mathrm{k}$-th column of the matrices considered [4].

Any linear dependence between the columns of matrix $M$, such as suggested by equation 5 becomes apparent by a (near) zero value of a singular value. For such values, for which $s_{k}=o$, equation 9 reads

$\mathrm{Mv}_{\mathrm{k}}=\mathrm{u}_{\mathrm{k}} \mathrm{S}_{\mathrm{k}}=\mathrm{u}_{\mathrm{k}} \times \mathrm{o}=\mathrm{o}$.

All those of the $(n-r)$ column vectors $v_{k}$ which result from the SVD algorithm for which $\mathrm{S}_{\mathrm{k}}=\mathrm{o}$ can thus be used as the weighting vectors $\beta$. Moreover, they form an orthonormal basis to a $(n-r)$-dimensional linear space, the so called zero space of the matrix $M(r=$ rank of the matrix $M$ ). The matrix comprising these basis vectors $v_{k}$ will be denoted by $V_{0}$. Consequently

$M V_{0}=0$

in which 0 represents a matrix of dimension $\mathrm{p} \times(\mathrm{n}-\mathrm{r})$ having zero elements only.

\subsection{Optimizing the fetal component in the re- sult}

The previous subsection has left us with matrix $V_{0}$, the columns of which can be used as weighting vectors for wiping out the maternal ECG. We now search for such linear combination $\alpha$ of these weighting vectors which results in a final weighting vector $w$ ensuring an optimal fetal component in the filter output:

$\mathbf{w}=\mathrm{V}_{\mathrm{o}} \alpha$

with $\alpha$ a $(n-r)$-dimensional loading vector for the weighting vectors $v_{k}$. To this end we select 
a time interval (again by visual inspection of the recorded signals) in which the fetal QRS complex is the sole constituent; let $\mathrm{q}$ be the number of samples involved. Then the signal matrix $\Phi$ reduces to $\Phi=F($ dimension $q \times n$ ). Application of the previously found weighting vectors $V_{0}$ to this data results in the matrix $\mathrm{A}=\mathrm{F} \mathrm{V}_{\mathrm{o}}$ and the search is for a linear combination $\alpha$ of its column vectors yielding an optimal result. If we now define optimal as meaning: having the maximum norm, the solution is easy. Let the singular value decomposition of matrix $A$ be

$\mathrm{A}=\mathrm{X} \Sigma \mathrm{Y}^{\mathrm{t}}$

with $\mathrm{X}, \Sigma$ and $\mathrm{Y}$ comparable to $\mathrm{U}, \mathrm{S}$ and $\mathrm{V}$ as used in equation 7 .

Since $\mathrm{A} Y=\mathrm{X} \Sigma$ can be expressed as

$A y_{k}=x_{k} \sigma_{k} \quad(k=1, n-r)$

it is evident that the unit vector $y_{k}$ resulting in a maximum power of $A y_{k}$ (left hand side) is simply the one corresponding to the largest singular value of matrix $\mathrm{A}$. We identify this vector as the required $\alpha$. Note that the restriction to unit vectors is essential to exclude all possible multiples of this vector yielding non significant multiples of the desired maximum power.

Since $A=F V_{0}$, we find that

$1=\mathrm{A} \alpha=\mathrm{F} \mathrm{V}_{\mathrm{o}} \alpha=\mathrm{Fw}$

is a linear combination of the fetal signals observed at the $\mathrm{n}$ leads with optimum resulting fetal power content. The vector $w=V_{0} \alpha$ is the desired optimal weighting vector.

As a final check on this result we consider a data matrix $\Phi$ corresponding to a time interval in which both the fetal and the maternal signals are present i.e. $\Phi=M+F$. Application of the weighting vector $\mathrm{w}$ to this data matrix $\Phi$ yields

$$
\begin{aligned}
1=\Phi w & =(M+F) w=(M+F) V_{o} \alpha \\
& =M V_{o} \alpha+F V_{o} \alpha
\end{aligned}
$$

The first term in the right hand side is zero by the result expressed in equation 11, the second term is the required filter output having a maximal fetal power content as required (= equation 13).

\section{Result}

The result and analysis of the filter to be presented here are based on a typical data set recorded during the later stage (38 weeks) of an uncomplicated pregnancy.

The abdominal FECG has been recorded in 28 leads simultaneously. The electrode placement is similar to the one shown in figure 1 of [10]. The recording system is identical to the one described in that same paper. Visual inspection over an $8 \mathrm{~s}$ segment of all recorded leads to the identification of the single lead in which the fetal signal is most clearly visible. This signal is shown in figure 1. Using this lead a time interval $\mathrm{T}_{\mathrm{M}}$ (see 2.2 ) of $88 \mathrm{~ms}$ (44 samples) and $\mathrm{T}_{\mathrm{F}}$ (see 2.3) of $72 \mathrm{~ms}$ (36 samples) was identified, corresponding to time segments of (pure) maternal and fetal QRS complexes. As a first step matrix $\Phi$ (dimension $28 \times 44$ ) related to interval $T_{M}$ was analyzed by computing its singular value decomposition (see 2.2). Inspection of the computed singular values revealed 5 singular values which were clearly much larger than the remaining $(28-5=23)$ ones. This indicated that the effective rank of this data matrix was of the order of 5. This rank was, cautiously, put at a larger value i.e. at the arbitrary value $\mathrm{r}=12$. This left a $28-12=$ 16 dimensional zero space $V_{0}$. Application of the individual columns of this matrix $V_{0}$ as weights to the recorded signals (i. e. computing $\left.\Phi V_{0}\right)$ results in 16 different weighted outputs, each having the property of a suppressed maternal component. The RMS (Root Mean Square) value of the fetal component in each these filter outputs was computed. In figure 2 two of the 16 filter outputs are shown having, respectively the maximal (top) and the minimal (bottom) fetal RMS value.

Note that in the optimal result (figure 2, top) the fetal signal is still barely visible. In the next 


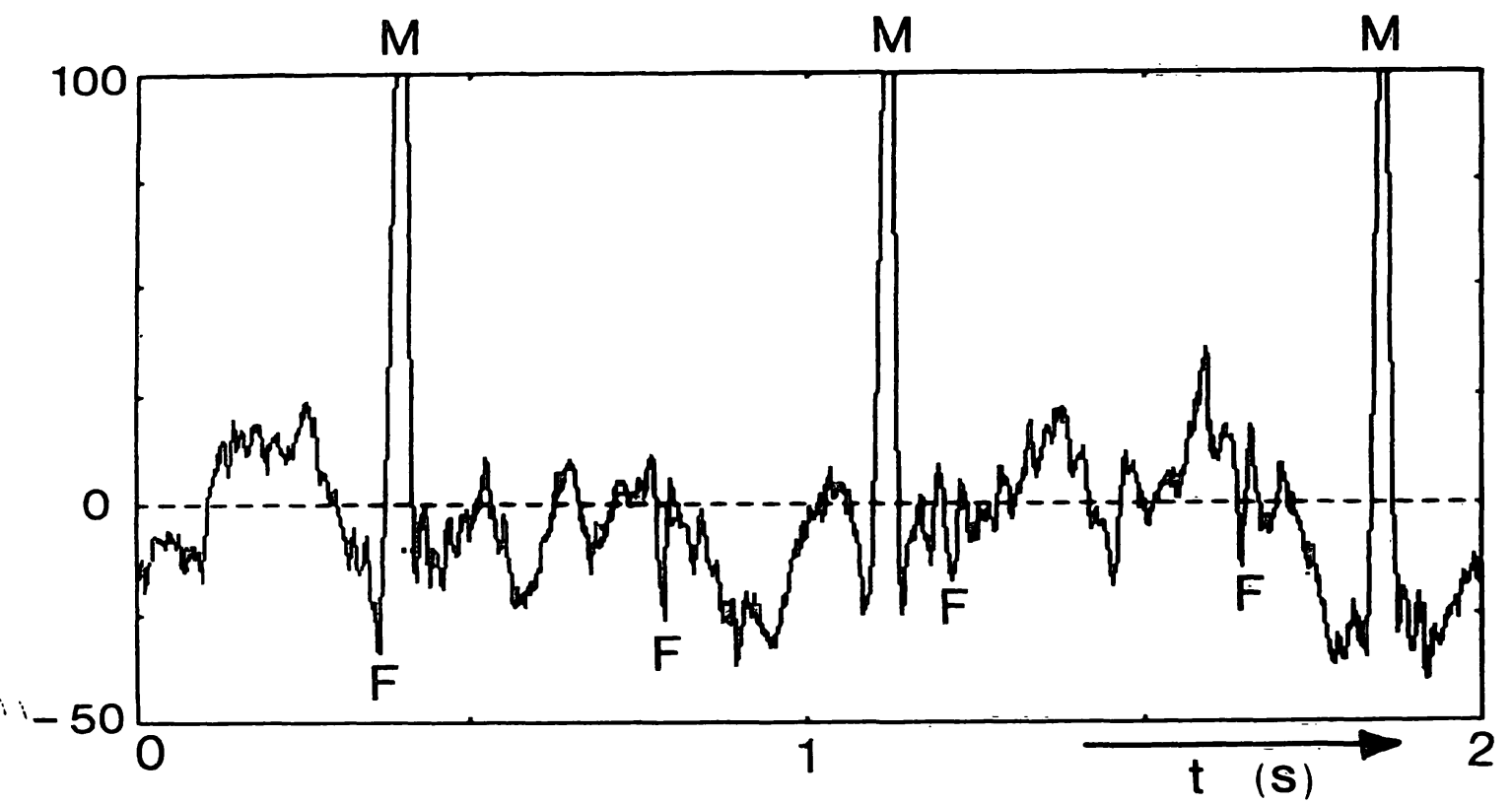

Figure 1. Waveform of 2 seconds of one of the 28 abdominal leads. Maternal complexes are easily recognized and indicated by M. Fetal complexes have been identified using the filter output (figure 3). Voltage scale expressed in $\mu \mathrm{V}$ as in all subsequent figures. Note relative poor quality of this lead which was the best one among the 28 signals available.
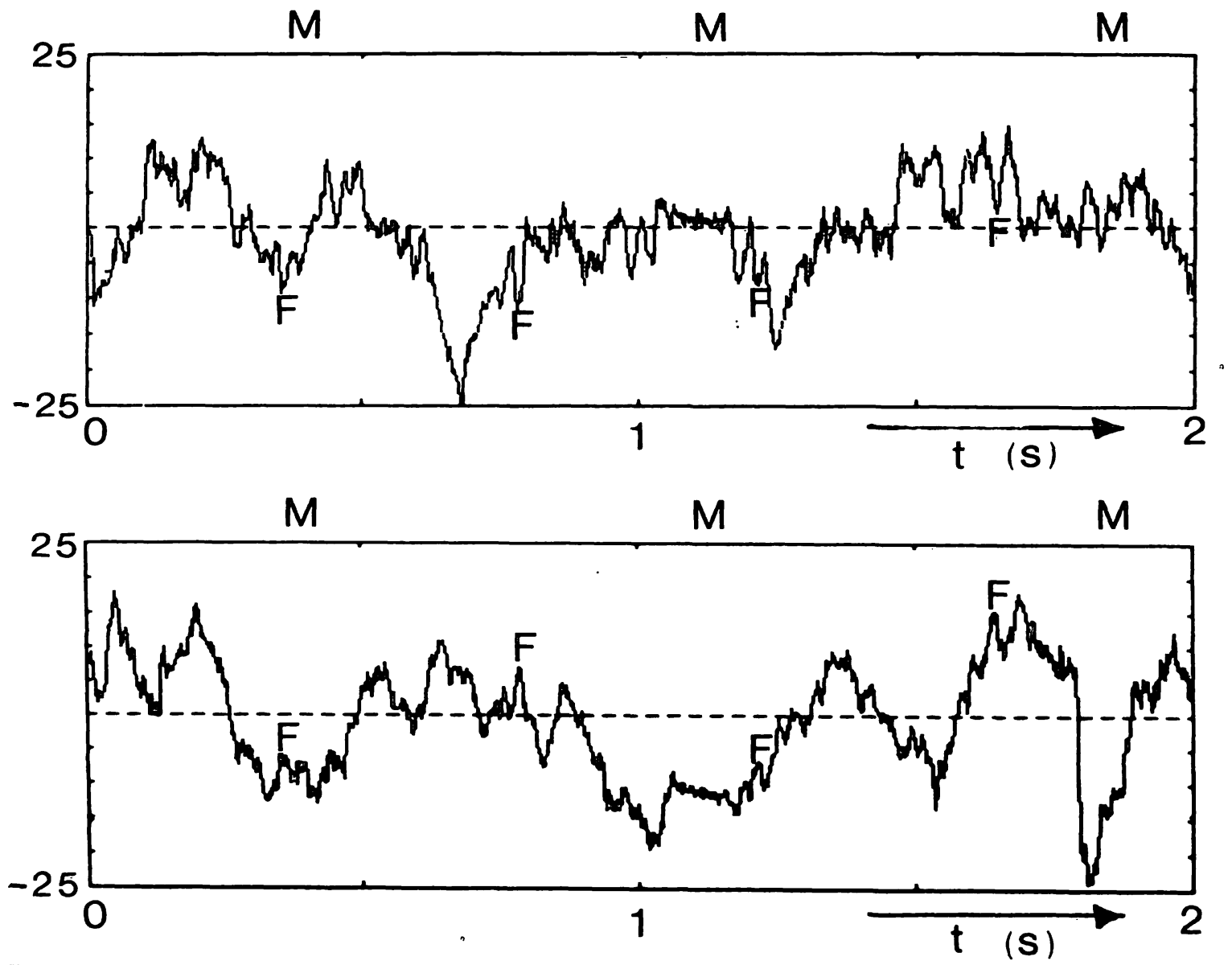

Figure 2.

Top: Result of the first step of the procedure (equation 11). Filter output having the maximal RMS value in the time interval $\mathrm{T}_{\mathrm{F}}$.

Bottom: Filter output (one of the columns of $\mathrm{MV}_{\mathrm{o}}$ in equation 11) having the smallest RMS value in the time interval $\mathrm{T}_{\mathrm{F}}$.

Time instants of occurence of maternal and complexes taken from figure 1. Note that maternal complexes are completely suppressed. 
step of the procedure (see 2.3) the data matrix $F$ related to interval $T_{F}$ is used to identify the largest singular value of the matrix $F V_{0}$ and the corresponding singular vector $\alpha$ (equation 13).

The optimal weighting vector $w$ is then taken to be $w=V_{o} \alpha$. The result of this optimal weighting vector applied to the recorded signals is shown in figure 3.

Note that in spite of the relatively poor quality of the input data the fetal complex is now clearly visible, in the output. The inclusion of the second step has clearly paid off.

Using the above data set a further analysis has been carried out in which the total number of leads in this procedure was successively reduced to a clinically more acceptable level. It was found that the procedure will still work when as few as $\mathbf{8}$ abdominal leads are used. However, the quality of the filter output, does gradually deteriorate with fewer leads. This is demonstrated in figure 4 which is the output of the optimum filter derived from and applied to a regularly spaced subset of 8 of the original 28 electrodes.

Moreover, in view of the variability in the fetal signals over the abdominal wall throughout pregnancy $[9,10]$, it would be advisable to take more than 8 leads, say no less than 10, regularly spaced over the abdomen. When applied to a larger set of recordings of relatively good quality the filter does provide an excellent fetal signal, as is shown in figure 4 of [10] in this issue.

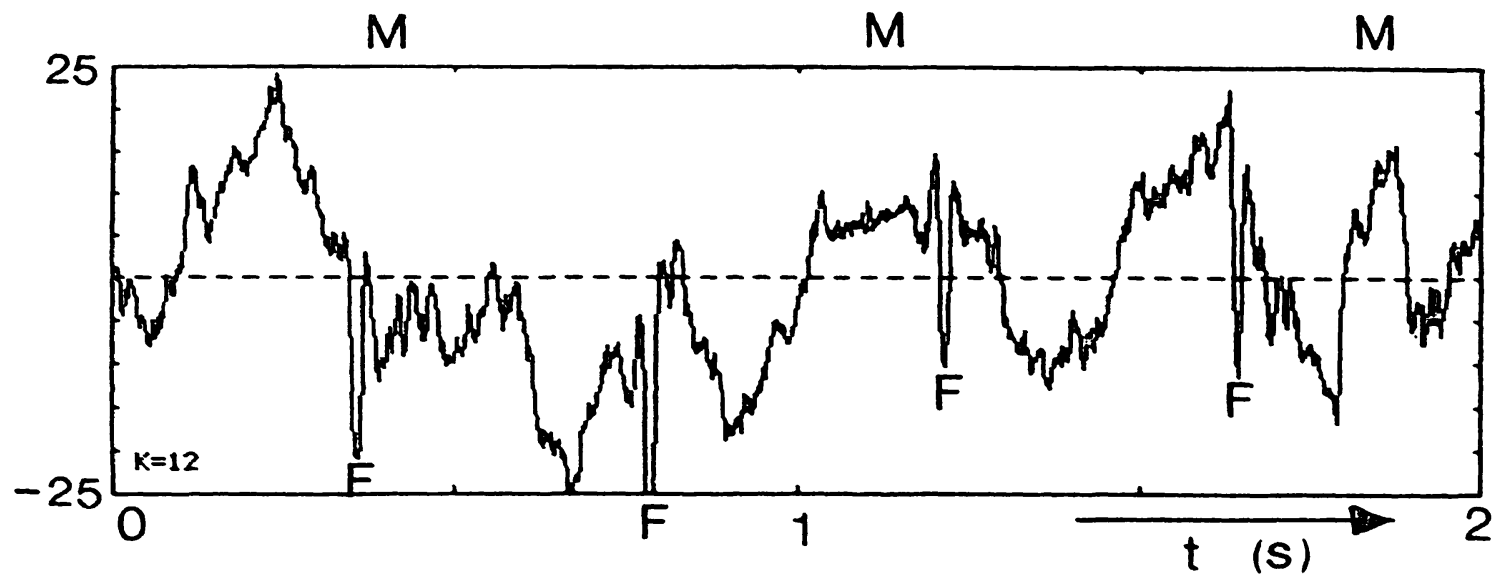

Figure 3. Optimal filter output based on 28 electrodes. Maternal signal completely absent. fetal signal clearly recognizable. $M$ and $F$ mark time instants of maternal and fetal complexes as before.

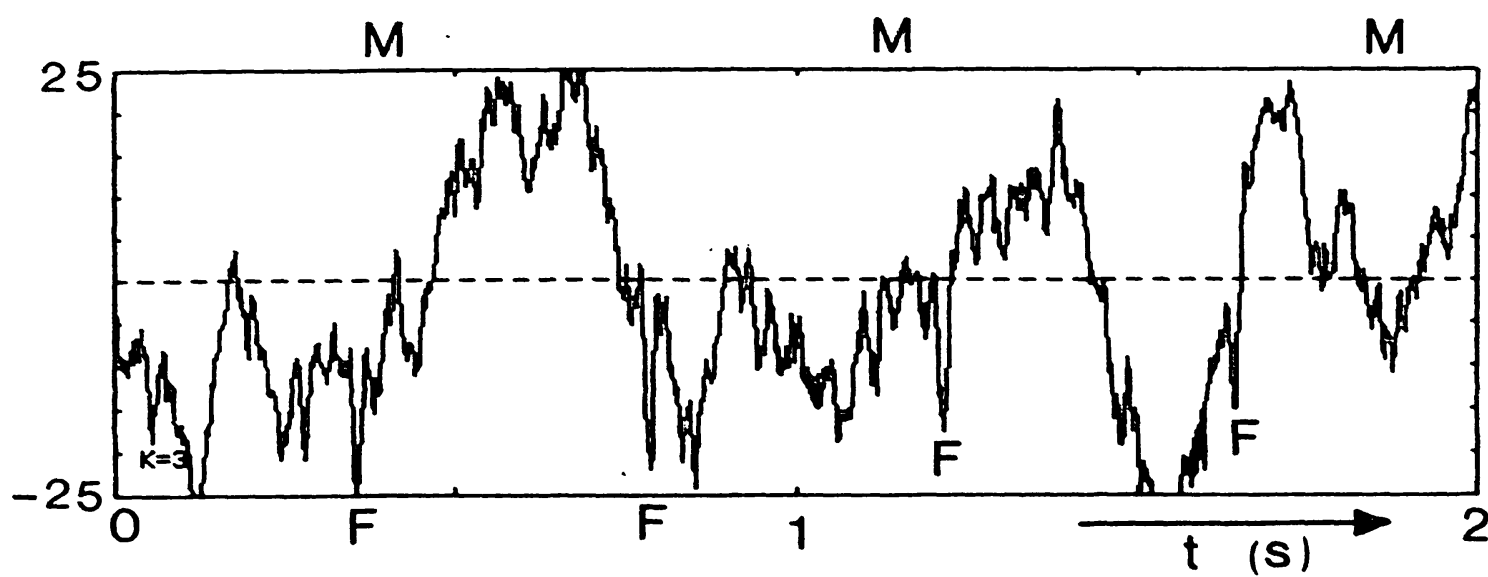

Figure 4. Filter output based on the entire procedure carried out on a subset of $n=8$ electrodes. The rank $k$ was put at $k=3$ leaving a subspace of dimension $8-3=5$ to search for maximal power of the fetal complex. 


\section{Summary}

One of the basic problems in the analysis of the rhythm and the shape of the fetal ECG (FECG) is the interference caused by the electrical activity of the maternal heart (MECG).

Methods devised for suppressing the maternal signals in the abdominally recorded leads obviously have to rely on differences in the characteristics of both kinds of signals. In the past various differences have been employed for this purpose such as differences in wave shape, frequency content and source location.

The method presented here is based on the latter principle. The electrical sources of the fetal and maternal heart are clearly separated in space. By employing multiple abdominal leads, a linear combination of the recorded signals can be formed which acts effectively as a spatial filter. As such the filtering characteristics depend exclusively on the separation inside the human body (the electrical volume conductor) and, as such, can be expected to be independent of the temporal aspects of the recorded signals. In particular, the obtained filter is unaffected by the occurrence of ectopic beats in either the fetal or the maternal heart.

The determination of the required filter (weighting coefficients) is carried out by using the technique of singular value decomposition (SVD) of the data matrix representing the sampled input signals. The filter effectively suppresses the maternal component in the filter output and optimizes the fetal component. The properties of this filter are demonstrated.

Keywords: Fetal monitoring, signal processing, singular value decomposition, spatial filter.

\section{Zusammenfassung}

\section{Räumliche Filterung des fetalen EKG's}

Eines der Hauptprobleme bei der Bestimmung der Herzfrequenz und der Kurvenform im fetalen EKG ist die Überlagerung mit elektrischen Signalen vom mütterlichen Herzen.

Um aus abdominalen fetalen Ableitungen mütterliche Signale herausfiltern zu können, eignen sich Methoden, die die charakteristischen Unterschiede zwischen beiden Signalen ausnutzen. Bisher hat man Unterschiede der Kurvenform, Frequenzunterschiede und unterschiedliche Orte der Signalentstehung für diesen Zweck herangezogen.

Die hier vorgestellte Methode berücksichtigt den zuletzt genannten Unterschied. Die elektrische Aktivität von mütterlichem und fetalem Herzen entsteht an räumlich klar voneinander getrennten Orten. Benutzt man mehre- re abdominale Ableitungen, so kann eine lineare Kombination der aufgezeichneten Signale gebildet werden, die effektiv als räumlicher Filter wirkt. Auf diese Weise hängt die Filtercharakteristik ausschließlich von der Auftrennung innerhalb des menschlichen Körpers (als elektrischer Leiter) $a b$, so daß man erwarten kann, daß das zeitliche Eintreffen der aufgezeichneten Signale ohne Einfluß bleibt. Im Besonderen: der Filter wird nicht durch das Auftreten ektopischer Schläge von fetalem oder mütterlichem Herzen gestört. Die Qualität der Filterung wird hier mit folgender Technik berechnet: die Datenmatrix mit den Eingangssignalen wird in Einzelwerte zerlegt. Der Filter unterdrückt tatsächlich die mütterliche Komponente bei Weiterleitung der Signale und optimiert das fetale Signal. Die Eigenschaften dieses Filters werden demonstriert.

Schlüsselwörter: Fetale Überwachung, räumliche Filter, Signalverarbeitung, Zerlegung in Einzelwerte.

\section{Résumé}

\section{Filtrage spatial de l'ECG fetal}

Un des problèmes de base de l'analyse du rythme et de la forme de l'ECG fœtal (FECG) est l'interférence provoquée par l'activité électrique du cœur maternel (MECG).

Les méthodes imaginées pour éliminer les signaux maternels au niveau des dérivations abdominales d'enregistrement doivent se fonder sur les différences qui existent au niveau des caractéristiques de chacun des signaux. Autrefois, on a utilisé de nombreuses différences dans ce but, par exemple les différences dans la forme des ondes, dans le niveau de la fréquence et l'emplacement du foyer.
La méthode que l'on présente est fondée sur ce dernier principe. Les foyers électriques du cœur fœtal et du cœur maternel sont nettement séparés dans l'espace. Une combinaison linéaire des signaux enregistrés peut être obtenue en utilisant de multiples électrodes abdominales; cette combinaison intervient effectivement comme un filtre spatial. Dans de telles conditions, les caractéristiques de filtrage dépendent exclusivement de la séparation à l'intérieur du corps humain (volume électrique conducteur) et de la sorte, on peut s'áttendre à ce qu'elles soient indépendantes des aspects temporels des signaux enregistrés. En particulier, la survenue de battements 
ectopiques, que ce soit au niveau du cœur fotal ou du cœur maternel, n'affecte pas le filtre obtenu.

La détermination du filtre requis (coefficients pondéraux) est menée à bien par la technique de décomposition en valeurs singulières de la matrice de données qui représente les signaux d'entrée recueillis. Effectivement, le filtre supprime la composante fœtale. On démontre les propriétés de ce filtre.

Mots-clés: Décomposition en valeurs singulières, filtre spatial, surveillance fæatal, traitement du signal.

\section{References}

[1] ARzBEACHER RC, DA BRoDY: The lead field: vector and tensor properties. In: NelsoN CV, DB GeSELowIrz (eds): The theoretical basis of electrocardiography. Clarendon Press, Oxford 1976

[2] BERgVELd P, WJH MEYER: A new technique of the suppression of the MECG. IEEE Trans Biomed Eng 28/4 (1981) 348

[3] Callaerts D, J Vanderschoot, J Vandewalle, W SANSEN, G VANTRAPPEN, J JaNSSENS: An adaptive on-line method for the extraction of the complete fetal electrocardiogram from simultaneous multilead recordings. $J$ Perinat Med, this issue

[4] Forsythe GE, MA Malcolm, CB Moler: Computer Methods for Mathematical Computations. Prentice-Hall, Englewood Cliffs, N. Y. 1977

[5] Geselowitz DB: Determination of multipole components. In: NeLSON CV, DB Geselowitz (eds): In theoretical basis of electrocardiography. Clarendon Press, Oxford 1976

[6] Golub GH, C ReInsCH: Singular Value Decomposition and Least Squares Solutions. Numer Math 14 (1970) 403

[7] HoRAN LG, NC Flowers: The relationship between the vector cardiogram and the actual dipole moment. In: NeLSON CV, DB Geselowitz (eds): The theoretical basis of electrocardiography. Clarendon Press, Oxford 1976

[8] LONGINI RL, TA Reichert, J MAN Cho YU: NearOrthogonal Basis Functions: A real time fetal ECG technique. IEEE Trans Biomed Eng 24/1 (1977) 39

[9] Oldenburg JT, M MaCKLIN: Changes in the conduction of the fetal electrocardiogram to the maternal surface during gestation. Am J Obstet Gynecol 129 (1977) 425
[10] OOSTENDORP TF, A VAN OOSTEROM, HW JONGSMA, PWJ VAN DONGEN: The potential distribution generated by the fetal heart at the maternal abdomen. $\mathrm{J}$ Perinat Med, this issue, pp 441

[11] Oosterom A van, J Alsters: Removing the maternal component in the fetal ECG using the singular value decomposition. In: RUTTKAY-NEDECKY I, P MACFarlaNe (eds): Electrocardiology '83. Excerpta Medica, Amsterdam 1984

[12] Pardi G, E Ferrarizi, I Cetin, S Rampello, G Baselli, S Cerutti, S Civardi: The clinical relevance of the abdominal fetal electrocardiogram. J Perinat Med, this issue, pp 371

[13] Rosén KG: Alterations in the fetal electrocardiogram as a sign of fetal asphyxia-experimental data with clinical implementation. J Perinat Med, this issue, $\mathrm{pp} 355$

[14] SaINI VD, D MaUlik: Computerized detection of low-level fetal signals in the maternal abdominal electrocardiogram. Comput Biol Med 15 (1985) 81

[15] Perinatal monitoring; 3rd Progress report - concerted action project No. I.1.1. of the third research programme in the field of Medical and Public Health Research. Spinhex B. V. Amsterdam 